Revista Destaques Acadêmicos, Lajeado, v. 10, n. 3, 2018. ISSN 2176-3070

DOI: http://dx.doi.org/10.22410/issn.2176-3070.v10i3a2018.1863

http://www.univates.br/revistas

\title{
CONTROLE DE DANOS EM FRATURAS EXPOSTAS: RELATO DE CASO
}

\author{
Bruno Vicenzo Thomas Bresolin ${ }^{1}$, Claudete Rempel ${ }^{2}$, Eduardo Rosa Otharan ${ }^{3}$
}

Resumo: Pacientes gravemente traumatizados, principalmente aqueles que apresentam hipotensão sistêmica ou traumatismo craniano, são casos em que existem controvérsias quanto à melhor oportunidade de intervenção terapêutica, de modo que, dependendo da ação realizada, pode-se desencadear respostas imunes e/ou inflamatórias. A realização do controle de danos reduz o trauma cirúrgico adicional através da fixação externa e cirurgia definitiva secundária. Será exposto um relato de caso com seguimento de 10 anos de um atendimento de uma fratura exposta de tíbia distal, atendido na emergência de um hospital da região do Vale do Rio Taquari/RS, onde foi realizado Controle de Danos, com aplicação de fixador externo inicial, com posterior conversão para osteosíntese definitiva de forma minimamente invasiva. Essa técnica demonstra evolução, melhora clínica e consolidações rápidas e eficientes das fraturas, fazendo com que a maioria dos pacientes volte às suas atividades laborais brevemente e sem prejuízos significativos.

Palavras-chave: Controle de Danos; Fixação externa; Fixação de Fratura

\section{Introdução}

Fraturas expostas são aquelas em que ocorre comunicação com o meio externo em decorrência de lesão de partes moles, sendo consideradas emergências ortopédicas (GIGLIO et al., 2015).

Pacientes gravemente traumatizados, especialmente aqueles que se encontram com hipotensão sistêmica ou traumatismo craniano, devem ser tratados com o objetivo de reduzir o trauma cirúrgico adicional através de fixação externa temporária e, posteriormente, a cirurgia secundária definitiva, ou seja, controle de danos ortopédicos, do inglês Damage Control Orthopedics

1 Acadêmico do Curso de Medicina da Univates.

2 Doutora em Ecologia. Docente do Centro de Ciências Médicas e dos Programas de PósGraduação em Ambiente e Desenvolvimento e em Sistemas Ambientais Sustentáveis.

3 Médico. Especialista em Ortopedia. Docente do Centro de Ciências Médicas. 
(DCO) (SMITH et al., 2015). Além desses problemas, a taxa de infecção em trabalho de análise retrospectiva de casos submetidos ao controle de danos ortopédicos em um pronto socorro de ortopedia de hospitalnescola com o objetivo de avaliar os pacientes com infecção pósDoperatória após serem convertidos para osteossíntese interna foi encontrada uma taxa de infecção de $13,3 \%$ além da verificação de erros técnicos na elaboração do fixador em 60,4\% das oportunidades (FONI et al., 2015).

O DCO é a combinação de uma técnica rapidamente executada e minimamente invasiva, sem acrescentar os riscos de uma cirurgia e sem interferir na qualidade final da osteosintese, visando estabilizar pacientes clinicamente instáveis, diminuindo perdas hemorrágicas e agilizando a transferência para unidade de atendimento intensivo (LEITE et al., 2011).

Relata-se, portanto, o caso com seguimento de 10 anos de um paciente que chegou a emergência apresentando fratura exposta de tíbia a qual foi tratada inicialmente com fixador externo temporário (Controle de Danos Ortopédicos) e conversão para osteosintese definitiva por mini incisão. O relato foi apreciado e aprovado pelo Comitê de Ética em Pesquisa, sob o Parecer: 1.855.072.

\section{Relato de caso}

Paciente do sexo masculino, 26 anos, ajudante de produção, atendido na emergência de um hospital da região do Vale do Rio Taquari/RS, devido à politraumatismo após acidente de trânsito (motocicleta).

O paciente apresentava Glasgow 15, trauma crânio-encefálico (TCE) com fratura de base de crânio e occipital, fratura exposta da tíbia distal (gustilo 3A) à direita, fratura exposta, sem deslocamento, do osso navicular do pé direito e lesões corto contusas múltiplas em pé, calcâneo e perna à direita (FIGURA1). Foi submetido à tratamento cirúrgico de emergência com colocação de fixador externo para controle de danos em tíbia à direita e sutura dos ferimentos (FIGURA 2). 
Figura 1 - Imagem que mostra fratura exposta da tíbia distal (gustilo 3A) à direita, fratura exposta, sem deslocamento, do osso navicular do pé direito e lesões corto contusas múltiplas em pé, calcâneo e perna à direita.

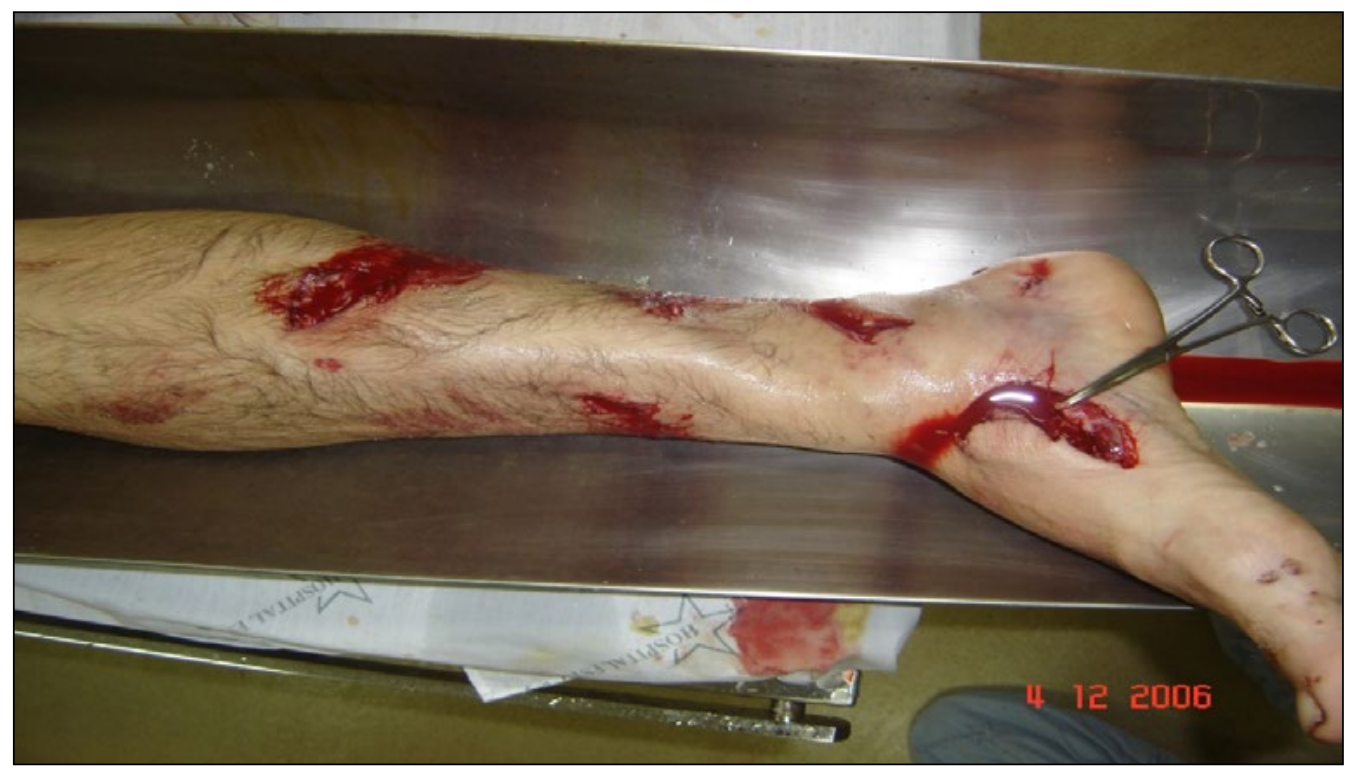

Figura 2 - Fixador externo para controle de danos em tíbia direita

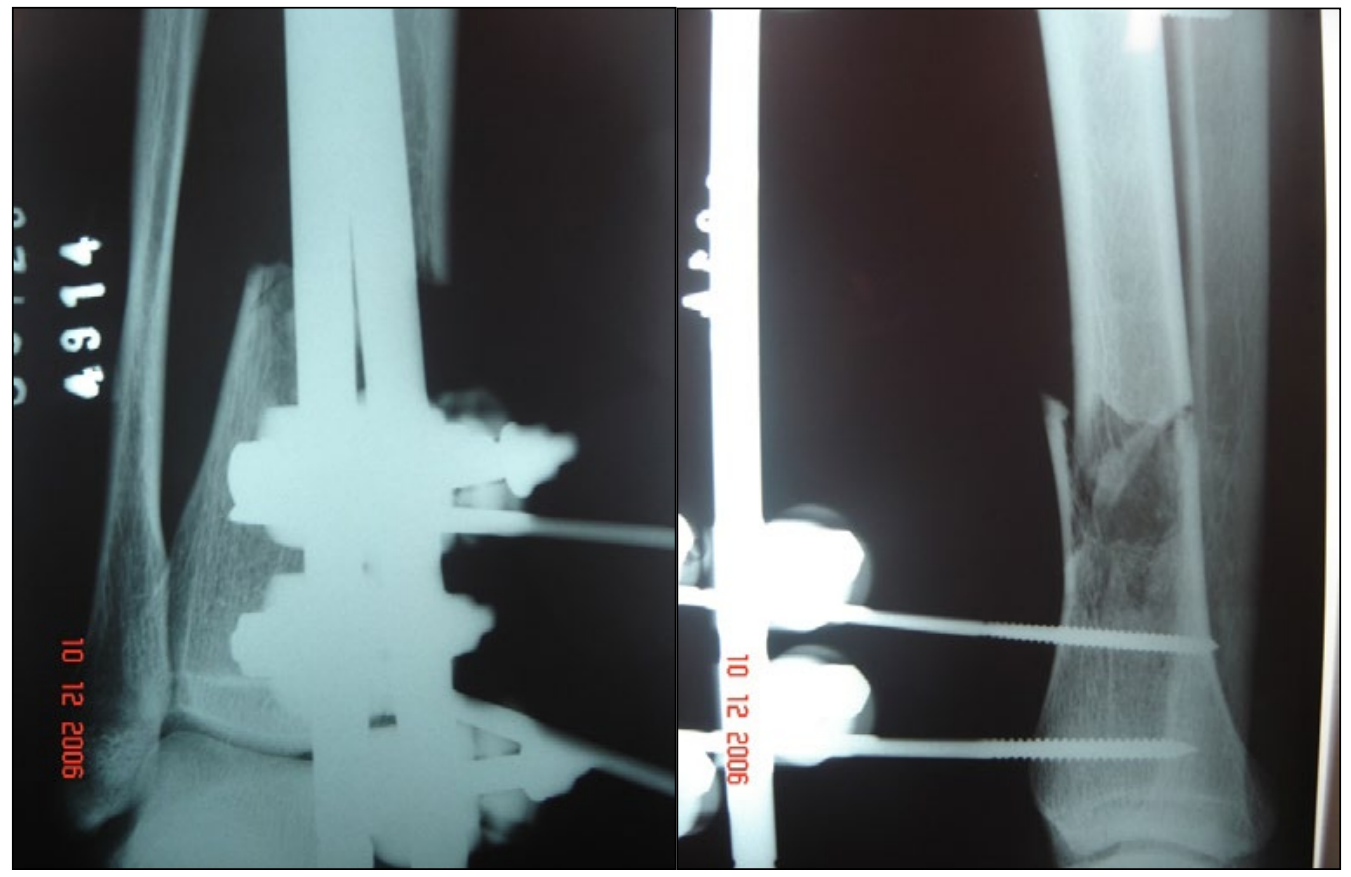


Permaneceu no pós-operatório imediato internado na UTI até apresentar melhora clínica. Após 14 dias, foi realizada a retirada do fixador externo para posterior conversão com osteossíntese minimamente invasiva com placa bloqueada em titânio e enxerto do ilíaco ipsilateral (FIGURA 3). Recebeu alta hospitalar do $2^{\circ} \mathrm{PO}$, apresentando controle radiológico com excelente redução da fratura. Encaminhado imediatamente após a alta para realização de fisioterapia motora. Foi liberado o apoio parcial após retirada dos pontos de sutura com 15 dias de $\mathrm{PO}$, mantendo-se controles radiológicos mensais até a alta definitiva no $6^{\circ}$ mês de PO. Nesta ocasião o paciente encontrava-se assintomático, com excelente evolução dos ferimentos e mobilidade articular tibiotársica normal.

Figura 3 - Osteossíntese minimamente invasiva com placa bloqueada em titânio e enxerto do ilíaco ipsilateral

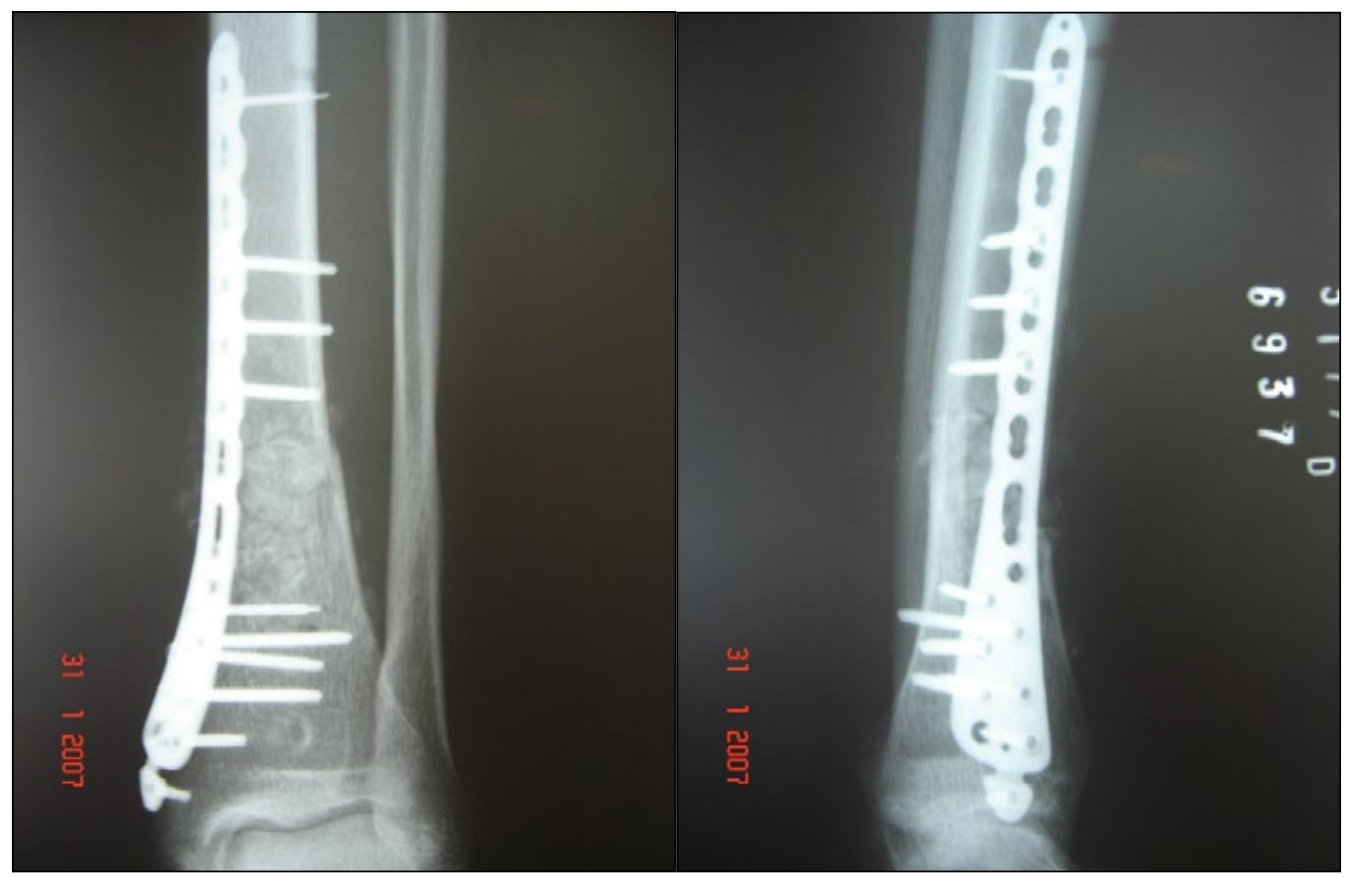

\section{Discussão}

As fraturas expostas são oriundas de um trauma com elevada energia e com associação de lesão das partes moles, definindo-se como fratura exposta, toda aquela em que ocorre ligação do seu foco com o meio externo contaminado por microrganismos (PACCOLA, 2001).

O método de tratamento destas fraturas evolui constantemente em virtude dos avanços clínicos e de pesquisas. Utilizou-se madeiras e molas para estabilizar os locais acometidos pelas fraturas e inserção de pinos por 
perfuração óssea com objetivo de evitar infecção e a necrose da pele. Apesar desta importante evolução quanto aos fixadores externos, ainda há muito a ser modificado, para que se evite a ocorrência de infecções, não consolidações e, principalmente, o agravamento dos danos fisiológicos do paciente (GIGLIO et al., 2015; SMITH et al., 2015; LEITE et al., 2011; PACCOLA, 2011; ROTBANDE; RAMOS, 2000).

Os fixadores externos têm suprido a necessidade dos ortopedistas que atuam nos setores de emergência pelo fato de sua instalação ser de rápida execução e baixa complexidade. Isenta subespecialistas, fluoroscopia e não requer material especial, apresentando grande versatilidade de uso. Portanto, seu uso torna menos provável as lesões iatrogênicas (CARDOZO et al., 2013).

Algumas medidas foram adaptadas diminuindo a probabilidade de óbito do paciente na mesa cirúrgica ou no pós-operatório, possibilitando uma posterior intervenção no momento adequado. Essa técnica, denominada, Controle de Danos, visa, intervir provisoriamente e que seja realizada a cirurgia definitiva somente após estabilização hemodinâmica e respiratória do paciente. Portanto, o tratamento é realizado depois que a estabilidade fisiológica esteja mantida e que a "tríade da morte" (composta por acidose metabólica, hipotermia e coagulopatia) não cause mais risco ao paciente (LIMA; ROCCO, 2007).

A técnica do Controle de Danos Ortopédicos tem como principais indicações aqueles pacientes que apresentam fatores como hipotensão (90 $\mathrm{mmHg}$ ), hipotermia $\left(\mathrm{T}<35^{\circ} \mathrm{C}\right)$, acidose metabólica $(\mathrm{pH}<7,2)$, instabilidade hemodinâmica, traumas de alta energia, múltiplas lesões penetrantes, entre outros. Após a análise e confirmação dos fatores necessários, geralmente, realiza-se o controle de danos ortopédicos em 3 principais etapas. A primeira etapa, classificada como operação abreviada, consiste na realização do controle temporário da hemorragia e uso do fixador externo temporário. A etapa seguinte, nomeada como reanimação na UTI, compreende a estabilização fisiológica do paciente. E, na última etapa, realiza-se o tratamento definitivo de todas as lesões existentes (ROTONDO; ZONIES, 1997; PARREIRA; SOLDÁ; RASSLAN, 2002).

Portanto, a técnica do controle de danos, que a 10 anos não era comum de ser utilizada, inicialmente foi usada em trauma abdominal exsanguinante com a finalidade de evitar tempos operatórios prolongados e prevenir o aparecimento da tríade letal, passou a ser aplicada em pacientes politraumatizados com fraturas de ossos pélvicos e longos. Com a utilização desse método nesses pacientes, evita-se o dano secundário causado por um procedimento inicial extenso, minimiza-se a morbimortalidade inicial, diminui-se a possibilidade de infecção e o paciente apresenta um melhor prognóstico funcional da estrutura acometida pelo trauma (MATHIEU et al. 2001). 


\section{Conclusão}

Pacientes oriundos de traumas graves e com associação de queda sistêmica da pressão ou com traumatismo craniano devem ser tratados inicialmente de forma provisória através do controle de danos ortopédicos. Com esse controle temporário da hemorragia, da infecção e dos danos estruturais obtém-se a estabilização hemodinâmica e respiratória do paciente para posterior cirurgia definitiva. Essa sequência de tratamento faz com que a recuperação do paciente seja mais rápida e que ocorra mínima (ou inexistente) perda funcional.

\section{Referências}

CARDOZO, R. T.; SILVA, L. G.; BRAGANTE, L. A.; ROCHA, M. A. Tratamento das fraturas diafisárias da tíbia com fixador externo comparado com haste intramedular bloqueada. Revista Brasileira de Ortopedia, v. 48, n. 2. P. 137-144, 2013.

FONI, N. O.; BATISTA, F. A. R.; ROSSATO, L. H. C.; HUNGIRA, J. O. S.; MERCADANTE, M. T.; CHRISTIAN, R. W. Infecção pósDoperatória nos pacientes submetidos ao controle de danos ortopédicos pela fixação externa. Revista Brasileira de Ortopedia, v. 50, n. 6, p. 625-630, 2015.

GIGLIO, P. N.; CRISTANTE, A. F.; PÉCORA, J. R.; HELITO, C. P.; LIMA, A. L. L. M.; SILVA, J. S. Avanços no tratamento das fraturas expostas. Revista Brasileira de Ortopedia, v. 50, n. 2, -. 125-130, 2015.

LEITE, C. G. A. C.; ARAÚJO, F. B.; MARQUES, J. P.C.; FARIA, N. M.; CAMBRAIA, N. V.; ARAÚJO, P. M.; CASTRO, P. R. C.; NEVES, S. C.; TEIXEIRA, E. M. Controle de dano ortopédico: Relato de caso. Rev Med Minas Gerais, v. 21, n. 2 supl 4, p. S1-S113, 2011.

LIMA, R. A. C.; ROCCO, P. R. M. Cirurgia para controle do dano: uma revisão. Rev Col Bras Cir. v. 34, n. 4, p. 257-263, 2007.

MATHIEU, L.; BAZILE, F.; BARTHÉLÉMY, R.; DUHAMEL, P.; RIGAL, S. Damage control orthopaedics in the context of battlefield injuries: The use of temporary external fixation on combat trauma soldiers. Orthopaedics \& Traumatology: Surgery \& Research, v. 97, p. 852-849, 2011.

PACCOLA, C. A. J. Fraturas expostas. Revista Brasileira de Ortopedia, v. 36, n. 8, p. 283-291, 2001.

PARREIRA, J. G.; SOLDÁ, S.; RASSLAN, S. Controle de danos: uma opção tática no tratamento dos traumatizados com hemorragia grave. Arq Gastroenterol., v. 39, n. 3, p. 188-197, 2002.

ROTBANDE, I. S.; RAMOS, M. R. F. Atualização em fixação externa: conceitos e revisão. Revista Brasileira de Ortopedia, v. 35, n. 4, p. 103-108, 2000. 
ROTONDO, F. M.; ZONIES, D. H. The damage control sequence and underlying logic. Surg Clin North Am. V. 77, n. 4, p. 761-777, 1997.

SMITH, W. R.; STAHEL, P. F.; SUZUKI, T.; PEACHER, G. Cirurgia para trauma musculoesquelético. In: SKINNER, H. B.; McMAHON, P. J. Current: Diagnóstico e tratamento: Ortopedia. 5ed. New York: McGraw-Hill, 2015. p.26. 